\title{
Diagnóstico da produção leiteira do município de Belo Oriente-MG ${ }^{1}$
}

\author{
Odílio Teles Teixeira ${ }^{2}$, Marcos Aurélio Lopes ${ }^{3}$, Uellington Corrêa ${ }^{4}$
}

\begin{abstract}
Resumo: Objetivou-se caracterizar produtores de leite do município de Belo Oriente, Mesorregião do Vale do Rio Doce, traçando o perfil médio da classe, com base na caracterização das propriedades, das famílias e dos sistemas de produção. Foram selecionados 25 agricultores familiares, no período de junho a agosto de 2015, que trabalhassem com bovinocultura. Foi aplicado, individualmente, o "Formulário de Diagnóstico da Propriedade Leiteira - Planilha EMATER", abordando as caracterizações do produtor, da propriedade, do rebanho e da produção de leite, adicionados da Planilha "Manejo da Bovinocultura de Leite", parte do "Diagnóstico da Unidade Produtiva Familiar" (Secretaria de Agricultura Familiar do MDA) sobre o manejo do rebanho. Os resultados foram tabulados em planilha eletrônica, calculando-se a média e o desvio padrão para cada variável. A área média das propriedades foi de 22,87 ha, com predomínio entre 11 a 20 ha (44\%). Na ocupação do solo, predominou pastagens formadas (69\%) e áreas de reserva (19\%); $48 \%$ das propriedades possuíam solos degradados. Verificou-se estrutura mínima de instalações com currais sem água, pisos inadequados no local de realização da ordenha das vacas. Concluiu-se que o município de Belo Oriente possui tradição em produção de leite, mas que a atividade não se desenvolveu, necessitando profissionalização e busca por outros mercados, fora dos limites do município, abrangendo as oportunidades oferecidas pela cadeia produtiva do leite.
\end{abstract}

Palavras-chaves: Agricultura familiar; Pecuária de leite; Extensão rural; Perfil do produtor; Gerenciamento da produção de leite.

\section{Diagnosis of dairy production in the city of Belo Oriente-MG}

\begin{abstract}
The objective of this study was to characterize milk producers in the municipality of Belo Oriente, Meso-region of Vale do Rio Doce, drawing the average profile of the class, based on the characterization of properties, families and production systems. Twenty-five family farmers were selected from June to August 2015 to work with bovine animals. The "Milk Farm Diagnosis Form EMATER Spreadsheet" was applied individually, addressing the characterization of the producer, the property, the herd and the milk production, added to the Worksheet "Management of Milk Cattle", part of the "Diagnosis of the Family Production Unit "(Department of Family Agriculture of MDA) on the management of the herd. The results were tabulated in spreadsheet, calculating the mean and standard deviation for each variable. The average area of the properties was 22.87 ha, with a predominance of 11 to 20 ha (44\%). In the land occupation, pastures were predominant (69\%) and reserve areas (19\%); $48 \%$ of the properties had degraded soils. There was minimal structure of facilities with pens without water, inadequate floors in milking; It was concluded that the municipality of Belo Oriente has tradition in milk production, but that the activity did not develop, requiring professionalization and search for other markets, outside the limits of the municipality, covering the opportunities offered by the milk production chain.
\end{abstract}

Keywords: Family farming; Dairy cattle; Rural extension; Producer profile; Management of milk production.

\footnotetext{
${ }^{1}$ Submetido em 05/07/2017 e a provado em 29/05/2018

${ }^{2}$ Especialista em Extensão Rural para o Desenvolvimento Sustentável; Empresa de Assistência Técnica de Minas Gerais - EMATER-MG, Belo Oriente - Minas Gerais, CEP: 35.195-000; E-mail:odilio.teixeira@emater.mg.gov.br

${ }^{3}$ Doutor em Zootecnia; Professor Titular, Universidade Federal de Lavras (UFLA), Departamento de Medicina Veterinária, Lavras - Minas Gerais, CEP:37200-000; Bolsista do CNPq; E-mail: malopes@dmv.ufla.br

${ }^{4}$ Mestre em Administração; Universidade Federal de Lavras (UFLA), Departamento de Administração e Economia, Lavras - Minas Gerais, CEP:37200-000; E-mail: uellington.correa@gmail.com
}

Revista Agropecuária Técnica, Areia-PB, v. 39, n. 2, p. 173-184, 2018

DOI: https://doi.org/10.25066/agrotec.v39i2.35136 


\section{Introdução}

A Região Metropolitana do Vale do Aço, criada por meio da lei complementar $\mathrm{n}^{\circ} 51$, de 30 de dezembro de 1998, é composta por quatro municípios principais, que tem sua economia baseada na produção de aço, que são Coronel Fabriciano, Ipatinga, Santana do Paraíso e Timóteo, e por mais vinte e quatro municípios, dentro os quais está Belo Oriente. O PIB de Belo Oriente está entre os maiores do Vale do Aço, destacando-se no setor industrial pela presença da Celulose Nipo Brasileira (CENIBRA) e na área de prestação de serviços. Até a década de 1920 a vida econômica do município girava em torno da agricultura, com destaque para o cultivo do milho, feijão, arroz, café, algodão e cana de açúcar. $\mathrm{Na}$ década de 1930, o setor agrícola perde espaço para a pecuária e o setor industrial, após a instalação da antiga Companhia Siderúrgica Belgo Mineira. A agropecuária teve seu auge na década de 1970, época em que o município era importante comercializador de produtos alimentícios (IBGE, 2010).

A agricultura é o setor que gera menos renda para a economia do município, mas socialmente tem sua representatividade. Em 2010, 11,33\% da população ativa esteve ocupada na agropecuária. $\mathrm{O}$ valor bruto adicionado pelo setor no PIB do município foi de $\mathrm{R} \$ 15.255 \mathrm{mil}$, em $2011 \mathrm{O}$ rebanho bovino era constituído de 8.500 animais, com produção de 2.200 mil litros de leite (IBGE, 2010).

Atualmente, a pecuária de leite ocupa a primeira atividade agropecuária explorada por agricultores familiares em número e importância socioeconômica no município (IBGE, 2010). Localmente, a cadeia produtiva do leite oferece poucos fornecedores de insumos e apenas uma indústria para captação da produção.

As propriedades possuem áreas extremamente exíguas, trabalham com a exaustão dos recursos naturais, empobrecendo os solos e diminuindo a oferta de água. Levantamentos sobre a renda rural para fins de emissão da Declaração de Aptidão ao Programa de Fortalecimento da Agricultura Familiar (DAP) (PRONAF) (Peixoto, 2008) indicam que os produtores de leite possuem baixa capacidade de investimento, além dos baixos níveis de participação em atividades associativas, baixa credibilidade nas suas organizações sociais e "empobrecimento". O índice de pobreza e desigualdade no município é de 45,65\% (IBGE, 2010). A utilização de tecnologias pouco responsivas e trabalhar abaixo do ponto de equilíbrio econômico para a atividade trazem sérios riscos de colapso da atividade, tornando a situação cada vez mais difícil de ser resgatada.

A indústria do leite, agora seriamente centralizada com a globalização e competitividade dos mercados, não oferece subsídios para o fortalecimento do setor, localmente, tornando-se também vulnerável, como elo da cadeia, mesmo utilizando-se de programas sociais, que deveriam fortalecer a classe produtora e a sustentabilidade da cadeia produtiva, como é o caso do "Programa Leite pela Vida", do Governo Federal.

Portanto, a atividade de gado de leite necessita ser gerida com profissionalismo, definindo a missão, a visão e as metas da empresa rural, mesmo que familiar, na abordagem dos conceitos de gestão da qualidade total. Assim, poder-se-ia atender as necessidades de todos os interessados no agronegócio: $\mathrm{O}$ cliente, representado pela agroindústria ou pelo mercado consumidor formal; os empregados, representados pela mão de obra familiar ou contratada; a sociedade, com relação ao cumprimento das legislações fiscais, trabalhistas, ambientais, normas relacionadas ao respeito e conforto animal e a política de manutenção do homem no campo; os proprietários, nesse caso os agricultores familiares, com relação ao retorno financeiro da atividade, preservando os valores culturais locais, incluindo a produção do leite e derivados tradicionais, livres de resíduos tóxicos e produtos contaminantes, preservando os recursos ambientais necessários à repetição dos processos de produção, processos esses preferencialmente de base agroecológica (Peixoto, 2008).

Objetivou-se caracterizar os produtores de leite do município de Belo Oriente, traçando o perfil médio da classe, com base nos sistemas de produção de leite explorados, nos entraves para desenvolvimento da atividade de bovinocultura leiteira, de forma a melhorar o entendimento dos processos, para que as futuras interferências, por meio da extensão rural, possam obter resultados mais promissores e comprometidos com o desenvolvimento sustentável. Especificamente, pretendeu-se caracterizar e classificar as famílias produtoras de leite, assim como as propriedades e as características dos sistemas de produção

Revista Agropecuária Técnica, Areia-PB, v. 39, n. 1, p. 173-184, 2018

DOI: https://doi.org/10.25066/agrotec.v39i2.35136 
utilizados, em função do processo administrativo e da tomada de decisões, assim como avaliar o conhecimento desses agricultores sobre economia, gestão e cadeia de produção do leite, de forma a direcionar e fortalecer o processo de extensão rural.

\section{Material e Métodos}

A presente pesquisa teve caráter quantitativo $\mathrm{e}$ qualitativo, e foi desenvolvido com 25 pequenos produtores de leite do município de Belo Oriente, MG, localizado na mesorregião do Vale do Rio Doce nas comunidades rurais de Braúna Grande, Bom Jesus do Bagre, Aviação, Eleutério, Esperança, São Sebastião de Braúnas, Ipê e Espirradeira, no período de junho a agosto de 2015.

O tipo climático, segundo a classificação de Köppen, é caracterizado como Aw tropical subquente semiúmido (IBGE, 2010), com temperatura média anual de $21,4{ }^{\circ} \mathrm{C}$, sendo a média máxima $29,2^{\circ} \mathrm{C}$ e média mínima $18,3^{\circ} \mathrm{C}$, com invernos secos e amenos e verões chuvosos e com temperaturas elevadas. A média de dados obtidos de precipitação pluviométrica é de 1.100 a $1.400 \mathrm{~mm} / \mathrm{ano}$ (Golfari, 1975).

As propriedades foram escolhidas utilizandose amostragem não probabilística por julgamento, levando-se em consideração os seguintes critérios: disponibilidade e qualidade dos dados zootécnicos e financeiros; consentimento e interesse dos pecuaristas na realização da pesquisa; facilidade de acesso por parte dos pesquisadores às fontes de evidências (Lopes et al., 2015).

O levantamento dos dados foi realizado por meio da aplicação do "Formulário de Diagnóstico da Propriedade Leiteira - Planilha EMATER", do tipo semiestruturado, abordando as caracterizações do produtor e da propriedade, do rebanho e da produção de leite, adicionados da Planilha "Manejo da Bovinocultura de Leite" do tipo estruturado, parte do "Diagnóstico da Unidade Produtiva Familiar", da Secretaria de Agricultura Familiar (SAF) do Ministério de Desenvolvimento Agrário (MDA).

Em relação ao produtor e à propriedade, o formulário aborda os aspectos de identificação, posse da terra, grau de instrução, local de residência, participação em entidades associativas, uso de meios de comunicação, participação em programas de assistência técnica, acesso do credito rural tipo de instalações, máquinas, equipamentos. Quanto aos aspectos do rebanho e da produção de leite, são abordados consulta às tecnologias mais utilizadas para atividade de gado de leite, uso de concentrados, volumosos, ureia, sal mineral, vacinas, controle de ectoparasitos e endoparasitos, inseminação artificial, transferência de embriões, controle leiteiro, controle zootécnico, manejo de ordenha, qualidade do leite, higiene de instalações, higiene de ordenha, controle contábil, alimentação do rebanho, tipo de pastagens, manejo de pastagens, participação em capacitações, adoção de boas práticas para produção de leite, oferta de água e energia elétrica, destino de dejetos e área destinada à produção de leite.

Parte do roteiro das entrevistas foi de carácter quantitativo, sendo elaborado em entrevista Survey, e parte foi de carácter qualitativo em questões abertas para aprofundamento dos temas e melhor entendimento das questões. Após o levantamento, os dados foram tabulados utilizando-se planilhas eletrônicas do software Microsoft Office Excel $^{\circledR}$ e apresentados de forma descritiva em percentuais. Os conteúdos qualitativos foram apresentados de forma descritiva.

\section{Resultados e Discussão}

\subsection{Caracterização da propriedade e da exploração leiteira}

A estratificação das propriedades por área demonstra um predomínio de propriedades com área entre 11 a 20 ha (44\%), seguido por propriedades com área entre 21 a 50 ha (32\%), com área entre 0 a 10 ha (16\%) e área entre 51 a 100 ha (8\%); não foi encontrada nenhuma propriedade com área superiora a 100 há, sendo a área média explorada de 22,87 ha. Menezes et al. (2014) relatam estratificação diferente, em levantamento feito na região Norte de Minas Gerais (34\% de 1 a 10 ha; $34 \%$ entre 11 e 50 ha; $16 \%$ de 51 a 100 ha, e $16 \%$ acima de 100 ha), mostrando as variações que ocorrem em mesorregiões distintas do estado de Minas Gerais.

Em relação ao uso do solo, as propriedades são ocupadas por pastagens formadas (69\%), áreas de reserva (19\%), cana-de-açúcar (Saccharum officinarum), capineira (Pennisetum purpureum) $(5 \%)$ e pastagens nativas $(5 \%)$.

Revista Agropecuária Técnica, Areia-PB, v. 39, n. x, p. 173-184, 2018

DOI: https://doi.org/10.25066/agrotec.v39i2.35136 
$\mathrm{Na}$ pesquisa realizada por Silvestre et al. (1996), sobre a caracterização das propriedades que utilizam predominantemente mão de obra familiar e exploram até 100 hectares para produção leite nas diferentes regiões de Minas Gerais, observou-se que 37,2\% das áreas das propriedades são ocupadas por pastagens nativas, $34,7 \%$ em pastagens formadas, 7,4\% em lavouras para produção de forragens, 5,5\% para cana-deaçúcar e capineira, 2,6\% para produção de grãos, $11,1 \%$ para matas e $1,6 \%$ para áreas com benfeitorias.

Em comparação com os resultados encontrados por Silvestre et al. (1996), observase que, os índices encontrados na região do Município de Belo Oriente são superiores aos índices das demais regiões do Estado de Minas, indicando que existe uma preocupação na formação de pastagens para a produção leiteira.

Em se tratando de conservação de solos, $48 \%$ dos produtores declararam ter áreas degradas na propriedade, contra 52\% que afirmaram ter solos conservados sem nenhuma ação de degradação. Ribeiro e Lírio (2005) citam como restrições técnicas que entravam a produção de leite na região de Bom Despacho, $\mathrm{MG}$, as pastagens e solos degradados.

Com relação às instalações e benfeitorias, verifica-se que a estrutura necessária à exploração da atividade é deficitária: sala de ordenha com cobertura (8\%); piso lavável (8\%), água disponível sob pressão (8\%), tanque de expansão individual foram encontradas em poucas propriedades (8\%), assim como trator e equipamentos (12\%) e ordenhadeira mecânica (24\%). Se considerada a classificação proposta por Menezes et al. (2014), os resultados apontaram que $66,7 \%$ das instalações estão em condições ruins, $30 \%$ em condições satisfatórias e 3,3\% em condições excelentes.

A estrutura necessária a explorações em fazendas ou em pequenas explorações leiteiras, no que concerne à segurança para produção de alimentos para consumo humano, não é atendida. Uma vez que as propriedades não possuem água potável ou sistema de tratamento adequado para sanitização de utensílios e equipamentos de ordenha, conforme recomendações da ANS (2015).

Cerqueira et al. (2006), ao afirmarem que a qualidade da água utilizada na produção de leite pode interferir na sua qualidade, concluíram que $100 \%$ das unidades de produção de leite utilizam água não tratada para fornecimento aos animais e para consumo próprio; resultados semelhantes aos obtidos no estudo em questão. Ribeiro e Lírio (2005) afirmaram que a água utilizada no ambiente de ordenha atua como via de transmissão de microrganismos para o leite e para animais, aumentando a incidência de doenças e reduzindo a qualidade do leite.

Apenas $8 \%$ possuem tanque de expansão individual para resfriamento do leite, enquanto Ribeiro e Lírio (2005), na região de Bom Despacho, citam que $49,9 \%$ dos produtores possuem esse equipamento importante na conservação da qualidade microbiológica do leite. Sousa et al. (2011) citam que apenas 4,96\% das propriedades, nas regiões Centro e Noroeste do Estado do Rio de Janeiro, possuem sala de ordenha e 22,13\% possuem ordenhadeira, condicionantes de importância nas boas práticas de ordenha para obtenção de leite de qualidade.

A existência de barramentos (20\%), irrigações (52\%), poços e cisternas (72\%) e desintegradores e picadeiras (96\%) demonstram as dificuldades com a distribuição e regularidade das chuvas no município, os problemas enfrentados para acesso dos animais à água e a necessidade de suplementação nutricional no período seco do ano. Confirmando essa tendência, $64 \%$ do acesso à água do rebanho ocorreu em bebedouros, e 36\% em córregos, riachos e lagos.

Quanto às atividades desenvolvidas, poucos possuem agricultura perene (16\%), normalmente pomar ou reflorestamento, seguido de culturas anuais (56\%), normalmente feijão e milho, explorados sob consórcio para consumo doméstico e de pequenos animais. Todos (100\%) têm como atividade principal a bovinocultura.

Wagner et al. (2004) afirmam que a diversificação das fontes de renda pelo desenvolvimento de outras atividades permitem a permanência na atividade de produção de leite e colocam a agricultura familiar como modelo sustentável de produção, independente da tecnologia aplicada.

\subsection{Caracterização dos produtores, organizações e interdependências}

Os produtores têm, em média, 3,36 membros da família participando das atividades rurais. A 
maioria (80\%) reside nas propriedades que exploram e poucos (20\%) residem em aglomerados urbanos, na sede do município ou distrito. O índice de $80 \%$ pode ser considerado representativo quando se analisa o processo de urbanização das populações no Estado e ao ser comparado com os resultados da pesquisa de Pêgo e Garcia (2016), que encontraram índice de $100 \%$ para produtores rurais familiares que exploram a pecuária leiteira e residem em suas propriedades na região da Zona da Mata em Minas Gerais.

Os pecuaristas entrevistados, produzem em média 74,6 L/leite/dia, estes intensificam a produção, uma vez que, $69 \%$ dos solos das propriedades são ocupadas por pastagens formadas. Entretanto, os animais possuem problemas de acesso à água e de suplementação nutricional no período seco do ano, além do que, a estrutura necessária à exploração da atividade é deficitária na maioria das propriedades; como em sala de ordenha com cobertura; piso lavável; água disponível sob pressão; tanque de expansão individual; trator e equipamentos; e ordenhadeira mecânica.

Com relação à produção pela área média explorada (22,87 ha), obtêm-se 3,26 L/ha/dia ou $1.189,9 \mathrm{~L} / \mathrm{ha} /$ ano. Observa-se que, apesar de fatores como a dificuldade dos animais ao acesso à água e de suplementação nutricional, os pecuaristas pesquisados podem obter maior ganho de produtividade por área explorada, e a assistência técnica continuada pode fornecer subsídios a estes para serem mais produtivos e promover a geração e ampliação de renda, além de fortalecer a agricultura familiar da região pesquisada.

Com relação à produtividade de leite por vaca, têm-se valores de $8,43( \pm 7,12) \mathrm{L} /$ vaca/dia e 4,57 $( \pm 4,96) \mathrm{L} /$ vaca total/dia; os altos desvios padrão demonstram as grandes diferenças entre as propriedades. Essa produção resulta em uma receita bruta média de 2,2 salários mínimos/mês e/ou de 26,30 salários mínimos/ano da comercialização do leite $(74,6 \mathrm{~L} / \mathrm{dia} \times 30$ dias = 2.238 litros de leite $\mathrm{x} \mathrm{R} \$ 0,85 / \mathrm{L}=2,2$ salários mínimos de $\mathrm{R} \$ 880,00$ e/ou de 74,6 L/dia x 365 dias $=27.229$ litros de leite $\times \mathrm{R} \$ 0,85 / \mathrm{L}=26,3$ salários mínimos de R \$ 880,00).

Considerando a quantidade média de machos disponíveis à comercialização, estima-se uma receita anual média adicional de 8,08 salários mínimos (132 machos de 0 a 12 meses, com peso médio 4,61@, + 28 machos de 13 a 24 meses, com peso médio de $10 @,+30$ machos com mais de 25 meses, com peso médio 16@, totalizando 1.368,52@, média de 54,74@/produtor ao preço médio do mercado local da @ de R\$130,00, divididos pelo valor do salário mínimo vigente de $\mathrm{R} \$ 880,00$ ).

A soma das duas receitas (leite e animais) totaliza 34,38 salários mínimos anuais como receita bruta total média da atividade para o grupo estudado. Embora não tenha sido registrado, grande parte dos produtores possuem outras fontes de renda, outro trabalho assalariado, imóveis de aluguel, comércio na zona rural e aposentadoria.

Sobre o período de tempo explorando a atividade, a maioria (60\%) tem mais de 10 anos, seguida pelo grupo entre 5 a 10 anos $(28 \%)$ e a minoria com até 5 anos na atividade (12\%), mostrando o tradicionalismo, a baixa taxa de renovação dos produtores na atividade, com predomínio de pessoas mais idosas.

Com relação à organização social, a maioria (68\%) dos produtores participa como associados em organizações rurais de moradores e em organizações sindicais (44\%); a minoria (16\%) não participa de nenhuma organização; não houve nenhuma participação em cooperativas, embora presentes no município.

O transporte da produção de leite, em 56\% dos casos, é de responsabilidade em conjunto dos produtores e da indústria. E, em $44 \%$ dos casos, os produtores fazem todo o transporte até o consumidor final (leite in natura ou processado na forma de queijo ou requeijão artesanais).

Menezes et al. (2014), no Norte de Minas, cita que $48 \%$ dos pequenos produtores fazem o transporte em grupo, assim como Ribeiro e Lírio (2005), na região de Bom Despacho, 78,4\% do transporte ocorre em grupo. Embora os produtores deste estudo participem de uma associação de moradores rurais e compartilhem nessa associação de um tanque de expansão coletivo, não conseguiram fazer o transporte do leite em grupo, como alternativa de busca de novos mercados.

No quesito assistência técnica e extensão rural, a EMATER - MG tem tradição de trabalho

Revista Agropecuária Técnica, Areia-PB, v. 39, n. x, p. 173-184, 2018

DOI: https://doi.org/10.25066/agrotec.v39i2.35136 
no município e todos os produtores (100\%) relataram ter recebido orientações in loco, ou no escritório local da empresa. Apenas um produtor (4\%) relatou receber assistência técnica particular; não houve relato de prestação de assistência técnica por sindicatos, cooperativas ou Organizações Não Governamentais (ONG's), assim como também não houve relato de participação em projetos como "Educampo", "Balde Cheio" ou "Minas Leite". Ribeiro e Lírio (2005), em Bom Despacho, MG, relatam que $28,4 \%$ das propriedades possuíam assistência técnica particular e que $34,7 \%$ não recebiam nenhum tipo de assistência técnica. Os resultados da pesquisa de Pêgo e Garcia (2016) demonstram que a assistência técnica rural do município de Miradouro, MG, é dada de forma aleatória sem nenhum programa específico ou direcionado, sendo constatado que $70 \%$ dos entrevistados não estão satisfeitos com a prestação do serviço.

\subsection{Caracterização do rebanho, do manejo e das tecnologias utilizadas}

Os índices zootécnicos influenciam na composição e evolução dos rebanhos, principalmente na taxa de natalidade, importante indicador da fertilidade do rebanho, seguido pela idade ao primeiro parto, taxa de descarte e taxa de mortalidade (Lopes et al., 2009).

Sobre a composição do rebanho, há predomínio das vacas em lactação (29\%) e vacas solteiras (16\%), seguido pelos bezerros até 1 ano (17\%) e bezerras até 1 ano (12\%). As novilhas de 2 a 3 anos (9\%), bezerras de 1 a 2 anos (6\%), bezerros de 1 a 2 anos e machos acima de 2 anos (4\%); reprodutores $(3 \%)$ representaram menor participação na composição do rebanho.

Silvestre et al. (1996) relata valores próximos para vacas em lactação $(26,55 \%)$, vacas solteiras $(14,88 \%)$, fêmeas e machos de até 1 ano $(12,24 \%)$, fêmeas de 1 a 2 anos $(9,23 \%)$, novilhas $(8,47 \%)$, machos de 1 a 2 anos $(11,86 \%)$ e machos acima de 2 anos $(4,52 \%)$ para médias em Minas Gerais.

Em um rebanho com composição de 60 a $69 \%$ de vacas em lactação, pode-se extrapolar um intervalo de partos entre 14 a 15,5 meses, idade ao primeiro parto entre 35 e 36 meses para mestiças Holandês-Zebu (HZ), período de lactação entre 8 a 9 meses, descarte na ordem de 10 a $15 \%$, produções de 1.500 a $2.500 \mathrm{~kg}$ leite/vaca/ano e produção de leite por dia de intervalo de partos entre 8 a $9 \mathrm{~kg}$ para mestiças de HZ (Ferreira e Miranda, 2008). Os pesquisadores estimam que o Brasil deixa de produzir cerca de 10 bilhões de litros de leite em função do longo intervalo de partos.

As composições dos rebanhos citados anteriormente sugerem uma combinação de indicadores de idade ao primeiro parto alta, com taxa de natalidade baixa e altas taxas de descarte e mortalidade dos rebanhos. A recria de novilhas não é feita pelos produtores em estudo, que têm optado pela aquisição de matrizes e pelo descarte de bezerros e bezerras em função do tamanho das propriedades e da priorização das pastagens para os rebanhos em lactação. Tal situação tem sido confirmada por informação verbal dos produtores por ocasião de elaboração de projetos de crédito rural.

Com relação à qualidade do leite e à higiene de ordenha, foi detectado que predomina entre os produtores $(96 \%)$ a desinformação sobre a Contagem de Células Somáticas (CCS) e a Unidade Formadora de Colônias (UFC). A maioria desconheciam esses conceitos, assim como não entendiam a correlação desses indicadores com a qualidade do leite. Tal fato mostra que os produtores desconhecem a qualidade do leite que produzem. Isso ocorre porque a indústria local, principal comprador de leite, não faz o pagamento do leite pela qualidade e, assim, não processa análises de CCS e UFC.

Estas análises são ferramentas úteis para monitoramento e avaliação da saúde do úbere com relação à incidência de mamite subclínica e à carga microbiológica contaminante do leite, conforme Instrução Normativa 62 (IN-62) do Ministério da Agricultura Pecuária e Abastecimento (MAPA), que determina taxas contaminantes menores que $100.000 \mathrm{UFC} / \mathrm{mL}$ de leite nas regiões Centro-oeste, Sudeste e Sul do Brasil, vigorando a partir de 01 de julho de 2016 (Brasil, 2004).

Um dos produtores analisados (4\%), buscando melhor remuneração pela produção, optou por fazer a comercialização para uma indústria de outro município, teve um resfriador individual instalado pela empresa na propriedade e passou a receber pagamento pela qualidade do leite (gordura, proteína, CCS e UFC). Segundo Lopes et al. (2011), em muitos laticínios, é praticada uma bonificação, em função da qualidade do leite 
produzido, que proporciona maiores receitas aos pecuaristas. Menezes et al. (2014), no Norte de Minas, encontrou resultados médios de 375.922 $( \pm 323.390)$ células $/ \mathrm{mL}$ leite; e $85 \%$ dos tetos analisados apresentaram Contagem Bacteriana Total (CBT) superior a $600.000 \mathrm{UFC} / \mathrm{mL}$ de leite.

Ainda sobre qualidade do leite, foi verificado que poucos produtores (15\%) utilizam a caneca telada ou de fundo escuro como método de diagnóstico de mastite clínica antes de cada ordenha. Sousa et al. (2011) descrevem que $83,33 \%$ e $59,97 \%$ dos produtores das regiões Noroeste e Centro do Rio de Janeiro, respectivamente, não utilizavam caneca telada ou de fundo escuro como método de controle de mamite clínica. Assim, estratégias de controle de mamite, como linha de ordenha, ordenha fora da sala de específica para evitar contaminação do ambiente e tratamento com antibiótico não poderão ser utilizados (Santos; Fonseca, 2007).

O California Mastit Test (CMT), para diagnóstico de mamite subclínica, não é utilizado ou conhecido pelos produtores. Testes rápidos e indiretos de avaliação da CCS tipo Somaticell ${ }^{\circledR}$, que poderiam ser executados na propriedade, também não são conhecidos. Pereira Neto et al. (2014) concluíram, no Estado de Goiás, que o método é satisfatório na detecção de resultados positivos ao exame microbiológico, recomendando como teste para diagnóstico individuais de mastite subclínica.

A desinfecção de tetos pré e pós ordenha (16 e $12 \%$, respectivamente), pré dipping e pós dipping, que deveria ser rotina na ordenha, é executada em poucas propriedades. Essas práticas contribuem para a diminuição dos índices de mamite nos rebanhos, diminuem os níveis de CCS e UFC e trabalham pela melhoria da qualidade do leite de conjunto (Galton et al., 1988).

Sousa et al. (2011), no Rio de Janeiro, citam que apenas $42,62 \%$ dos produtores faziam pelo menos uma atividade para controle da mamite, e Menezes et al. (2014), no Norte de Minas, relatam que $15 \%$ dos tetos examinados apresentaram resultados de CMT positivos. Mesmo assim, poucos (20\%) produtores, deste estudo, declararam ter tido casos clínicos. Conclui-se que a maioria (85\%) dos produtores não utilizam nenhum método de controle ou prevenção de mamite. $\mathrm{O}$ descarte usual dos três primeiros jatos de leite, considerado leite residual (leite secretado na ordenha anterior, que fica armazenado no canal do teto até a ordenha seguinte), usando a caneca telada ou de fundo escuro, contribui muito para a diminuição da carga bacteriana contaminante do leite de conjunto e para a qualidade final da matéria-prima para a indústria (Sousa et al., 2011).

A única ação dos produtores com relação à mamite clínica é o tratamento com antibióticos, de aplicação intramamária após os sintomas clínicos. Mas doses terapêuticas adequadas, período de tratamento por 5 a 7 dias, antibiograma do leite para monitoramento da eficácia do tratamento e o descarte do leite residual contaminado pelo uso de antibióticos não foram observados, mesmo porque não se tem assistência veterinária regular. Segundo Santos e Fonseca (2007), as três principais ações para controle da mamite se baseiam na diminuição da exposição aos patógenos pelo controle ambiental, aumento da resistência imunológica da vaca e antibioticoterapia.

Martins et al. (2008), em trabalho desenvolvido em Goiás, concluíram que é necessário educação e treinamento sobre obtenção higiênica do leite, higiene de equipamentos de ordenha, execução de programas de controle de mamite e manutenção do sistema de refrigeração pós-ordenha, para que se possa melhorar a qualidade microbiológica do leite cru produzido em Goiás.

Três grupos de produtores $(48 \%)$ de comunidades distintas utilizam tanque de resfriamento de leite coletivo. Na região, as indústrias que remuneram o leite por qualidade geralmente não aceitam $\mathrm{o}$ resfriamento em tanques coletivos.

O teste diagnóstico de tuberculose bovina não foi feito em nenhuma propriedade, mesmo que o "Programa Nacional de Controle e Erradicação de Brucelose e Tuberculose" torne obrigatório o exame de tuberculose em caso de transporte interestadual de animais para reprodução, transporte para participação em eventos agropecuários e leilões, conforme Instrução Normativa $\mathrm{n}^{\mathrm{o}} 6$ (IN 06) do Ministério da Agricultura Pecuária e Abastecimento (MAPA) (Brasil, 2004). Sousa et al. (2011) observaram que, em $81,15 \%$ das propriedades estudadas, foram tomadas medidas de controle contra

Revista Agropecuária Técnica, Areia-PB, v. 39, n. x, p. 173-184, 2018

DOI: https://doi.org/10.25066/agrotec.v39i2.35136 
Tuberculose, no Rio de Janeiro, medidas essas obrigatórias no caso de produção de leite tipo "B".

Outras tecnologias, como a recuperação de pastagens a cada cinco anos (24\%), segunda ordenha $(20 \%)$ ou utilização de inseminação artificial (20\%), como método principal de reprodução, são pouco utilizadas. Silvestre et al. (1996), em Minas Gerais, citam o uso da inseminação artificial (14\%) e da segunda ordenha (39,4\%), enquanto Menezes et al. (2014), no Norte de Minas, relatam em $10 \%$ o uso de inseminação artificial.

Entre as tecnologias pesquisadas, a cura do umbigo dos bezerros ao nascimento com solução de iodo é a mais adotada (80\%) pelos produtores. Mas a rotação de culturas (8\%) em áreas de lavouras anuais é pouco usada; as queimadas ainda são utilizadas (4\%); a ordenha sem bezerros ao pé da vaca e o plantio direto na palha não são utilizadas por nenhum dos produtores.

Outras tecnologias utilizadas por todos os produtores pela necessidade premente, em função do risco de surtos no rebanho e prejuízos por mortalidade de animais são as vacinas por Clostridium sp. (100\%).

Em função de fiscalização e multas decorrentes do "Programa Nacional de Controle de Febre Aftosa", política sanitária do Ministério de Agricultura Pecuária e Abastecimento (MAPA), executado no estado pelo Instituto Mineiro de Agropecuária (IMA), obrigando todos os criadores de bovídeos domésticos a vacinarem seus rebanhos contra Febre Aftosa. Verificou-se, neste estudo, que $100 \%$ dos entrevistados vacinaram seus animais contra a febre aftosa. Essa medida sanitária é exigida para exportação de carne bovina ao mercado externo (Lage et al., 2006).

Menezes et al. (2014), no Norte de Minas, relata vacinação contra febre aftosa e Clostridium sp em $100 \%$ e $70 \%$ das propriedades, respectivamente. Sousa et al. (2011), no Rio de Janeiro, citam 85,9\% e 65\%, respectivamente.

A adubação orgânica com esterco bovino é prática usual feita por todos (100\%) os produtores, mesmo porque é necessário fazer a limpeza das instalações e o descarte adequado dos resíduos. Comumente é aplicado na capineira ou canavial de forma fresca, após o corte e entre as linhas. A utilização de defensivos no controle de carrapatos, bernes, mosca do chifre e verminoses dos bovinos é realizada por $96 \%$ dos pecuaristas entrevistados. Silvestre et al. (1996) citam que, dos produtores entrevistados, em Minas Gerais, 93,5\% utilizam tratamentos contra carrapatos, bernes e verminoses dos bovinos. Rebanhos originários de intensa seleção genética, assim como a agricultura tecnificada são muito dependentes de defensivos químicos, geram alta dependência tecnológica e, consequentemente, impactos negativos de contaminação do meio ambiente, em função do uso de defensivos químicos tóxicos, na lógica da produção sustentável da agricultura familiar (Gomes, 2003).

A maior parte dos produtores (92\%) não utiliza as práticas agroecológicas em substituição às medidas agrotóxicas disponíveis no mercado para controle de carrapatos, bernes, mosca do chifre e vermes intestinais dos bovinos. Começa a surgir, na região em estudo, uma tendência ao uso de homeopáticos e fitoterápicos no controle de carrapatos, bernes e mosca do chifre, mas os entrevistados consideram que os produtos ainda são caros e a confiabilidade é questionada. Resultados semelhantes são relatados por Menezes et al. (2014), na região do Norte de Minas.

A utilização do tratamento de sementes com pesticidas é prática comum entre $56 \%$ daqueles que plantam milho para grão.

A análise de solos (28\%), base para a recomendação de corretivos do $\mathrm{pH}$ e adubação dos solos, como a calagem (32\%), o uso de adubos químicos (36\%) e a adubação em cobertura (32\%) ainda são pouco utilizadas, considerando a necessidade de melhoria dos índices de produção e produtividade ou a utilização sem orientação técnica adequada.

Foi verificado que próximo da metade dos produtores $(48 \%)$ oferece apenas sal comum (cloreto de sódio) ao rebanho e que pouco mais da metade (52\%) dos produtores utiliza sal mineralizado contendo macro e micronutrientes, com teores próximos à recomendação. Conhecimentos consolidados sobre nutrição de bovinos ainda continuam sem aplicação por parte do grupo estudado. Como é o caso da mineralização dos rebanhos bovinos de corte e leite, necessário em função das demandas diárias

Revista Agropecuária Técnica, Areia-PB, v. 39, n. 1, p. 173-184, 2018

DOI: https://doi.org/10.25066/agrotec.v39i2.35136 
de macro (cálcio e fósforo) e micronutrientes (zinco, cobre, manganês e selênio) (Peixoto et al., 2005).

Estudos anteriores descrevem índices diferentes no uso do sal mineral na média do estado de Minas Gerais (92,3\%) e no Rio de Janeiro (22,13\%) (Silvestre et al., 1996; Sousa et al., 2011).

Quanto à suplementação volumosa, predominou $(60 \%)$ a oferta para vacas em lactação pelo período de 4 a 5,9 meses/ano. Raros produtores arraçoam por mais de 6 meses $(2 \%)$. Poucos, por 2 meses ou menos (12\%) e $20 \%$ deles por 2 a 4 meses.

A suplementação concentrada não é utilizada por mais da metade $(56 \%)$ das propriedades em nenhuma categoria animal; os demais (44\%) utiliza algum suplemento concentrado apenas para as vacas em lactação, adquirido no comércio local; e nenhuma propriedade produz seu concentrado, ou parte dos ingredientes para a formulação da dieta na propriedade. Tal fato mostra que a nutrição das vacas em lactação é desbalanceada e contribui para obtenção de baixos índices de produção e produtividade.

Silvestre et al. (1996), em Minas Gerais, afirmam que $10,5 \%$ dos produtores não utilizam ração balanceada e que $32,6 \%$ utilizam algum tipo de alimento concentrado. Sousa et al. (2011), no Rio de Janeiro, citam que $15,57 \%$ dos produtores utilizam ração balanceada.

O controle leiteiro, necessário ao balanceamento nutricional da dieta, a seleção genética dos animais mais produtivos no sistema de produção e ao controle financeiro da atividade, é pouco $(4 \%)$ praticado entre produtores. A maioria (96\%) não conhece o período de lactação médio do seu rebanho, dificultando a oferta de concentrados para as vacas em lactação, inviabilizando a seleção genética do rebanho e dificultando a elaboração do custo de produção por animal. Silvestre et al. (1996) citam que apenas 13,8\% dos produtores de Minas Gerais fazem o controle leiteiro.

Outros fatores como o intervalo de partos e indicadores zootécnicos (16\%), necessários ao controle da produção e produtividade e a seleção genética do rebanho não são monitorados. Outros autores relatam sobre a porcentagem dos produtores que fazem o controle zootécnico:
Silvestre et al.(1996) (32,10\%), em Minas Gerais; Menezes et al. (2014) $(66,6 \%)$, no Norte de Minas; e Sousa et al. (2011) $(25,23 \%)$, no Rio de Janeiro.

Poucas $(16 \%)$ propriedades anotam nascimentos de bezerros e poderiam calcular o intervalo de partos médio do rebanho e de cada animal em particular. A falta da coleta de dados e análise dos indicadores zootécnicos impedem a boa administração da propriedade, assim como a correção dos problemas de manejo encontrados (Almeida et al., 2016).

Da mesma forma, os registros de despesas e receitas da atividade em estudo não são contabilizados na maioria $(96 \%)$ das propriedades, resultando em falta de importante informação, necessária ao bom gerenciamento da atividade. Silvestre et al. (1996) citam que, na média, em Minas Gerais, apenas 15,4\% dos produtores fazem a contabilidade da propriedade, enquanto que Ribeiro e Lírio (2005) relatam menos (3\%), em Bom Despacho, MG; e Sousa et al. (2011) citam 42,86\% no Rio de Janeiro.

Ferramenta importante na estruturação da atividade, o acesso ao crédito rural $(60 \%)$ tem contribuído para o desenvolvimento da agricultura familiar. Positivamente, os produtores em estudo acessaram uma ou mais vezes o credito por meio do PRONAF (Peixoto, 2008) e investiram em suas propriedades, principalmente para aquisição de matrizes. Silvestre et al. (1996), em Minas Gerais, citam acesso por 32,1\%; Menezes et al. (2014) relatam 66,6\%, na região Norte de Minas, e Sousa et al. (2011) citam índices de 25,23\% dos produtores acessando credito rural no Rio de Janeiro. Parte dos produtores $(40 \%)$ não acessou o crédito, ficando mais predisposta ao colapso da atividade por falta de recursos, investimentos e custeio para renovação dos rebanhos, modernização da estrutura e investimento em produção de forragens.

Esta pesquisa objetivou a caracterização de pequenos produtores de leite, suas organizações e seus empreendimentos no município de Belo Oriente, essa qualificação pretende direcionar a assistência técnica a ser oferecida pela extensão rural, visando alcançar resultados mais promissores. A elaboração de programas com foco no desenvolvimento sustentável para a atividade de bovinocultura, envolvendo todos os 
elos da cadeia produtiva e todos os atores potenciais é de extrema importância. Devendo-se observar no processo:

a) A organização dos produtores e suas entidades associativas;

b) A busca por mercados potenciais e nichos de agregação de valor com remuneração por qualidade;

c) O planejamento da produção de forma a ter escala e volume a ser comercializado coletivamente;

d) A construção participativa do processo a partir das características e cultura locais;

e) A utilização de tecnologias apropriadas às condições eco socioambientais, buscando ser economicamente viável, socialmente responsável, ecologicamente correto e culturalmente diverso, para que se possa contribuir para o desenvolvimento do município.

Sugere-se a elaboração de diagnósticos complementares a cada período de desenvolvimento do programa para avaliação e redirecionamento para os objetivos fins. A oportunidade da Chamada Pública do Leite, Contrato 208/2014 Lote 31, de assistência técnica aos produtores do município, em execução, deve ser aproveitada para início das atividades, devendo-se manter o programa por prazo suficiente para que se possa obter resultados mensuráveis.

\section{Conclusão}

Os conhecimentos do nível tecnológico, do estágio de desenvolvimento da atividade de bovinocultura diagnosticado, parcialmente, neste levantamento, assim como os valores locais da cultura são importantes como ponto inicial de partida para a criação de programas que busquem o desenvolvimento da atividade de leite no município.

Os resultados apontaram que cerca de $80 \%$ dos produtores residem nas propriedades. Em média, há 3,36 membros da família participando das atividades rurais. Dentre os produtores entrevistados cerca de $60 \%$ possuem mais de 10 anos explorando a atividade. A produtividade média é de 74,6 L/leite/dia, sendo que à área média das propriedades é de 22,87 ha e a receita bruta total média auferida na venda de leite e animais totalizou 34,38 salários no período analisado. Os resultados apontaram ainda que $66,7 \%$ das instalações estão em condições ruins, e em relação à qualidade do leite e à higiene de ordenha, $96 \%$ dos produtores desconhecem sobre a Contagem de Células Somáticas (CCS) e a Unidade Formadora de Colônias (UFC). Entretanto, $100 \%$ dos produtores relataram ter recebido assistência técnica da EMATER - MG.

Belo Oriente possui a tradição e cultura na exploração de pecuária mista pela agricultura familiar, mas a atividade se mostra nos estágios iniciais de desenvolvimento, necessitando se profissionalizar, para se tornar mais produtiva e competitiva, e buscar nichos e oportunidades de mercado outros que não só os oferecidos apenas localmente, considerando a cadeia produtiva do leite como um todo.

\section{Agradecimentos}

Os autores agradecem à Empresa de Assistência Técnica e Extensão Rural de Minas Gerais (EMATER - MG), por possibilitar a realização desta pesquisa, e ao $\mathrm{CNPq}$, pela concessão da bolsa de produtividade em pesquisa do segundo autor.

\section{Referências}

Agência Nacional de Saúde Suplementar - ANS. Instrução Normativa $n^{0}$ 61, de 04 de dezembro de 2015. Dispõe sobre a regulamentação dos parágrafos $2^{\circ}$ e $3^{\circ}$ do artigo $7^{\circ}$ da Resolução Normativa - $\mathrm{RN} \mathrm{n}^{\circ} 364$, de 11/12/2014, que dispõe sobre o Fator de Qualidade a ser aplicado ao índice de reajuste definido pela ANS para prestadores de serviços hospitalares.

http://www.ans.gov.br/component/legislacao/?view=legis lacao\&task $=$ TextoLei\&format=raw\&id=MzE0OA==

Almeida, A. C. de; Santos, C. A. dos; Menezes, I. R.; Teixeira, L. M.; Costa, J. P. R.; Souza, R. M. de. Perfil sanitário de unidades agrícolas familiares produtoras de leite cru e adequação à legislação vigente. Ciência Animal Brasileira, v.17, n.3, p.303-315, 2016. http://dx.doi.org/10.1590/1089-6891v17i314597

Brasil. Instrução Normativa $n^{\circ} 06$, de 12 de janeiro de 2004. Aprova o Regulamento Técnico do Programa Nacional de Controle e Erradicação da Brucelose e Tuberculose Animal. Diário Oficial da União, Brasília, DF, 12/01/2004. Seção 1, p. 6. http://www.idaron.ro.gov.br/portal/legislacao/arquivos/ex ibir.ashx?arquivo $=2 \&$ especie $=$ Instrucao_Normativa\&Nu $\underline{\mathrm{m}=6 \& \mathrm{ano}=2004}$ 
Brasil. Lei Complementar $\mathbf{n}^{\circ} \mathbf{5 1}$, de 30 de dezembro de 1998. Institui a Região Metropolitana do Vale do Aço, dispõe sobre sua organização e funções e dá outras providências. Diário do Executivo-"Minas Gerais", Belo Horizonte, $\quad$ MG, 31/12/1998. http://www.siam.mg.gov.br/sla/download.pdf?idNorma= $\underline{2148}$

Cerqueira, M. M. O. P.; Picinin, L. C. A.; Fonseca, L. M. da; Souza, M. R. de; Leite, M. de O.; Penna, C. F. de A. M.; Rodrigues, R. Qualidade da água e seu impacto na qualidade microbiológica do leite. In: Mesquita, A. J.; Dur, J. W.; Coelho, K. O. Perspectivas e avanços da qualidade do leite no Brasil. Goiânia: Talento, 2006. p.273-290. https://www.researchgate.net/profile/Leorges Fonseca/pu blication/267784170_Qualidade_da_agua_e_seu_impacto na qualidade microbiologica do leite/links/552930a70 cf2779ab78f7095/Qualidade-da-agua-e-seu-impacto-naqualidade-microbiologica-do-leite.pdf

Empresa de Pesquisa Agropecuária de Minas Gerais. Diagnóstico da pecuária leiteira do município de Barroso. Belo Horizonte: EPAMIG, 2007. 26p. http://www.epamig.br/download/diagnostico-da-pecuarialeiteira-municipio-de-barroso/

Ferreira, A. M.; Miranda, J. E. C. Medidas de eficiência da atividade leiteira: índices zootécnicos para rebanhos leiteiros. 2. ed. Juiz de Fora: Embrapa Gado de Leite, 2008. 8p. https://www.embrapa.br/gado-de-leite/busca-depublicacoes/-/publicacao/595838/medidas-de-eficienciada-atividade-leiteira-indices-zootecnicos-para-rebanhosleiteiros

Galton, D. M.; Petersson, L. G.; Merrill, W. G. Evaluation of udder preparations on intramammary infections. Journal of Dairy Science, v.71, n.5, p.1417-1421, 1988. https://doi.org/10.3168/jds.S0022-0302(88)79700-3

Golfari, L. Zoneamento ecológico do estado de Minas Gerais para reflorestamento. Belo Horizonte: PND, 1975. 65p. (Série Técnica, 3).

Gomes, S. T. Diagnóstico e perspectivas da cadeia produtiva do leite no Brasil. 2003. 16p. Monografia (Bacharelado em Zootecnia) Universidade Federal de Viçosa, Viçosa, 2003. http://arquivo.ufv.br/der/docentes/stg/stg_artigos/Art_164 \%20-\%20DIAGNOSTICO \%20E\%20PERSPECTIVAS\% 20DA\%20CADEIRA\%20PRODUTIVA\%20DO\%20LEI TE\%20NO\%20BRASIL\%20\%286-1-03\%29.pdf

Instituto Brasileiro de Geografia e Estatística IBGE. Cidades. Belo Oriente: IBGE, 2010.
Disponível em:

http://cidades.ibge.gov.br/xtras/home.php >. Acesso em: 18/02/2015.

Lage, A. P.; Roxo, E.; Muller, E. E.; Poester, F. P. V.; Cavalléro, J. C. M.; Ferreira Neto, J. S.; Mota, P. M. P. C.; Gonçalves, V. S. P. Programa nacional de controle e erradicação da brucelose e da tuberculose animal (PNCEBT): manual técnico. Ministério da Agricultura, Pecuária e Abastecimento, Brasília: Ministério da Agricultura, Pecuária e Abastecimento, 2006.2 188p. http://www.adapar.pr.gov.br/arquivos/File/GSA/PECEBT IMANUAL PNCEBT.pdf

Lopes, M. A. Demeu, F. A.; Rocha, C. M. B. M. da; Costa, G. M. da; Franco Neto, A.; Santos, G. dos. Influência da contagem de células somáticas no impacto econômico da mastite em rebanhos bovinos leiteiros. Arquivos do Instituto Biológico. v.78, n.4, p.493-499, 2011. http://www.scielo.br/pdf/aib/v79n4/a03v79n4.pdf

Lopes, M. A. Moraes, F. de; Carvalho, F. M.; Peres, A. A. C.; Bruhn, F. R. P.; Reis, E. M. B. The effect of technological levels on profits of milk production systems participating in the "full bucket" program: a multicase study. Semina: Ciências Agrárias, v.36, n.4 p.29092922, 2015. http://dx.doi.org/10.5433/1679$\underline{0359.2015 \mathrm{v} 36 \mathrm{n} 4 \mathrm{p} 2909}$

Lopes, M. A.; Cardoso, M. G.; Demeu, F. A. Influência de diferentes índices zootécnicos na composição e evolução de rebanhos bovinos leiteiros. Ciência Animal Brasileira, v.10, n.2, p.446-453, 2009. https://www.revistas.ufg.br/vet/article/view/1661

Lopes, M. A.; Reis, E. M. B.; Ferrazza, R. A. Formulário de diagnóstico da propriedade leiteira. Brasília: Embrapa, 2015. 19p. https://www.embrapa.br/busca-de-publicacoes/publicacao/1063787/administrando-a-propriedadeleiteira-cartilhas-elaboradas-conforme-a-metodologia-erural

Lopes, M. A.; Silva Dias, A.; Melo Carvalho, F. de; Ribeiro Lima, A. L.; Ghedini Cardoso, M.; Almeida do Carmo, E. Efeito da escala de produção nos resultados econômicos de sistemas de produção de leite na região de Lavras (MG, Brasil), em 2004 e 2005. Archivos Latinoamericanos de Producción Animal, v.16, n.3, p.129-137, 2008. http://www.bioline.org.br/pdf?la08018 
Martins, M. E. P.; Nicolau, E. S.; Mesquita, A. J. de; Neves, R. B. S.; Arruda, M. L. T. Qualidade de leite cru produzido e armazenado em tanques de expansão no estado de Goiás. Ciência Animal Brasileira, v.9, n.4, p.1152-1158, 2008. https://www.revistas.ufg.br/vet/article/view/1829

Menezes, I. R.; Almeida, A. C. de, Pinto, M. S.; Velasco, F. O.; Maia, F. P.; Rodrigues, G. V. Caracterização de unidades agrícolas familiares produtoras de leite no Norte do Estado de Minas Gerais. Revista do Instituto de Laticínios Cândido Tostes, v.69, n.3, p.153-163, 2014. https://doi.org/10.14295/2238-6416.v69i3.342

Pêgo, R. G.; Garcia, P. A. Agricultura familiar do distrito de Varginha no município de Miradouro - Minas Gerais: um estudo de caso. Pensar Acadêmico, v.14, n.1, p.48-60, 2016. https://doi.org/10.21576/rpa.2016v14i1.5

Peixoto, M. Extensão rural no Brasil: uma abordagem histórica da legislação. Textos para Discussão, n.48, p.1-50, 2008. http://www2.senado.leg.br/bdsf/handle/id/136891

Peixoto, P. V.; Malafaia, P.; Barbosa, J. D.; Tokarnia, C. H. Princípios de suplementação mineral em ruminantes. Pesquisa Veteterinária Brasileira, v.25, n.3, p.195-200, $2005 . \quad$ http://dx.doi.org/10.1590/S0100736X2005000300011

Pereira Neto, M.; Rangel, A. H. N.; Araújo, V. M. de; Lima Júnior, D. M. de; Medeiros, H. R. de; Novaes, L. P. Avaliação de métodos rápidos para análises da contagem de células somáticas no leite cru de tanques de resfriamento. Revista do Instituto de Laticínios Cândido Tostes, v.69, n.3, p.16-22, 2014. https://doi.org/10.14295/2238-6416.v69i3.274

Ribeiro, H. M. D.; Lírio, V. S. Desempenho da cadeia produtiva de leite do município de Bom Despacho - MG. 2005. 13p. Monografia (Bacharelado em Ciências Econômicas) Universidade Federal de Viçosa, Viçosa, 2005.

Santos, M. V.; Fonseca, L. F. L. Estratégias para controle de mastite e melhoria da qualidade do leite. São Paulo: Manole, 2007. 314p.

Silvestre, J. R.; Reis, D. L. dos; Ávila, I. F. S. de; Vidal, L. S.; Nunes, M. R.; Carvalho, M. A. de; Cardoso, V. C. Pecuária leiteira nas pequenas propriedades: diagnóstico da pecuária leiteira nas pequenas propriedades do estado de Minas Gerais. Belo Horizonte: EMATER-MG, 1996. 232p.

Sousa, M. R. P. Ristow, A. M.; Nogueira, E. B.; Torres Filho, R. A.; Cortez, M. A. S. Caracterização de pequenas unidades produtoras de leite na região Centro e Noroeste do Estado do Rio de Janeiro. Revista Brasileira Ciências Veterinária, v.18, n.2/3, p.79-84, 2011. https://doi.org/10.22409/rbcv.v18i2-3.228

Wagner, S. A.; Gehlen, I.; Wiest, J. M. Padrão tecnológico em unidades de produção familiar de leite no Rio Grande do Sul relacionado com diferentes tipologias. Ciência Rural, v.34, n.5, p.1579-1584, 2004. http://dx.doi.org/10.1590/S010384782004000500039 